\title{
A 56-year-old woman with ampullary adenocarcinoma and acute pancreatitis
}

\section{Mujer de 56 años con adenocarcinoma de la ampolla de Vater y pancreatitis aguda}

\author{
V. M. Santos ${ }^{1,2}$, R. B. Villaça ${ }^{3}$, C. S. Marinho ${ }^{2}$, P. R. M. Nogueira Junio ${ }^{3}$, C. O. Maia ${ }^{3}$, \\ A. G. O. Camilo ${ }^{2}$
}

\begin{abstract}
A 56-year-old woman was admitted with jaundice, and laboratory data were indicative of pancreatitis, which recurred in spite of adequate clinical and nutritional management. The patient was an overweight diabetic using metformin, who had antecedents of cholelithiasis and recent cholecystectomy. Clinical and laboratory features were not conclusive about the cause of this acute pancreatitis. However, imaging data contributed to diagnosis suspicion, and the histopathology study of the transpapillary biopsy confirmed the ampullary adenocarcinoma. Whipple's surgery was the procedure of choice, associated with radical lymphadenectomy, followed by an uneventful outcome. Recrudescence of signs and symptoms of acute pancreatitis, with elevated serum levels of bilirrubins and of hepatic canalicular enzymes, should enhance the suspicion index about periampullary tumors. High levels of CA 19-9 can constitute a useful marker of this condition. Transpapillary biopsy can characterize the diagnosis of ampullary malignancies.
\end{abstract}

Key words. Acute pancreatitis; Adenocarcinoma; Ampullary carcinoma; Endoscopic-retrograde cholangiopancreatography (ERCP); Transpapillary biopsy.

\section{RESUMEN}

Se presenta el caso de una mujer de 56 años, que presentaba ictericia y cuyos exámenes de laboratorio fueran indicativos de pancreatitis. Presentó recurrencia a pesar de las medidas clínicas y nutricionales adecuadas. La paciente era diabética, con sobrepeso, tomaba metformina y con antecedentes de colelitiasis y reciente colecistectomía. Los datos clínicos y del laboratorio no fueron concluyentes acerca del origen de esta pancreatitis aguda. Sin embargo, los estudios de imagen contribuyeron a la sospecha del diagnóstico; los estudios de citologia exfoliativa y de biopsia transpapilar confirmaron un adenocarcinoma ampular. La cirugía de Whipple fue el procedimiento de opción, asociado con linfadenectomía radical, con resultado favorable. El recrudecimiento de señales y síntomas de pancreatitis aguda, con niveles séricos elevados de bilirrubina y de enzimas hepáticos debe reforzar el índice de sospecha acerca de tumores ampulares. La elevación de CA 19-9 en el suero puede ser un marcador útil de esta entidad. La realización de biopsia transpapilar suele ayudar a obtener el diagnóstico.

Palabras clave. Pancreatitis aguda. Adenocarcinoma. Carcinoma ampular. Colangiopancreatografia endoscopica retrógrada (CPER). Biopsia transpapilar.
1. Catholic University Medical Course. BrasiliaDF. Brazil

2. Internal Medicine Department of Armed Forces Hospital. Brasilia-DF. Brazil

3. Gastroenterology Division of Armed Forces Hospital. Brasilia-DF. Brazil

Recepción: 1 de mayo de 2012

Aceptación provisional: 11 de mayo de 2012

Aceptación definitiva: 14 de mayo de 2012

\author{
Correspondencia: \\ Vitorino Modesto dos Santos \\ Armed Forces Hospital \\ Estrada do Contorno do Bosque s/n \\ Cruzeiro Novo \\ 70658-900, Brasília-DF, Brazil \\ E-mail: vitorinomodestos@gmail.com
}




\section{INTRODUCTION}

Tumors of the ampulla of Vater are very uncommon gastrointestinal neoplasms, which account for $0.2 \%$ of the cases ${ }^{1-3}$. This low incidence may be due to under recognition at an early phase, due to nonspecific clinical features and diagnosis challenges. Most often, these tumors present with painless jaundice or recurrent episodes of acute pancreatitis ${ }^{2}$, and the prognosis is usually favorable if the diagnosis is established early ${ }^{1-3}$. Imaging studies (e.g. ultrasonography, computed tomography, magnetic resonance, endoscopicretrograde cholangiopancreatography, and endoscopic ultrasonography) constitute the main tools to localize the tumor, but final diagnosis is based on histopathology data. Echoendoscopy constitutes a very useful procedure to detect the presence, extension and lymph node metastasis of ampullary and periampullary tumors ${ }^{2,3}$. In addition, this method can rule out main differential diagnosis like residual choledocholithiasis. Adenocarcinoma is the most common histopathological type of ampullary tumors, but other carcinomas (e.g. adenosquamous, mucinous, papillary) are described $^{3}$. Resection can be curative in near half of the patients, with a five-year survival of $33-68 \%^{3}$; the better schedule of adjuvant chemotherapy and radiotherapy is not consensual ${ }^{1,2}$. Acute pancreatitis has an incidence ranging between 4-100 cases per 100,000 population, with a tendency to increase and variable morbidity and mortality rates ${ }^{4,5}$. In some cases, acute pancreatitis is idiopathic, and the exact mechanisms of less common predisposing conditions are not completely understood. The purpose of this report is to emphasize the diagnosis suspicion of acute pancreatitis due to ampullary tumor, mainly if clinical and laboratory improvement is not observed after adequate medical treatment.

\section{CASE REPORT}

A 56-year-old woman with diabetes mellitus and arterial hypertension had pain with progressive intensity in epigastrium and irradiating to the left flank during 15 days, in addition to nausea, vo- miting and fever $\left(\leq 38^{\circ} \mathrm{C}\right)$ with no shivering. She was submitted to a cholecystectomy four months before, and was in regular use of enalapril, glibenclamide and metformin. Previous diagnosis of cholelithiasis and her surgical treatment were performed in other health service. Physical examination showed BMI $27.1 \mathrm{Kg} / \mathrm{m}^{2}$, jaundice $(3+)$, pain on palpation of epigastrium and of the left flank, and absence of masses or visceromegaly. Laboratory tests on admission: red cells $3.85 \times 10^{12} / \mathrm{L}$, hemoglobin $11,1 \mathrm{~g} / \mathrm{dL}$, hematocrit $33,8 \%$, leukocytes $7.1 \times 10^{9} / \mathrm{L}$ (57\% neutrophils), platelets $314 \times 10^{9} / \mathrm{L}$; urea 29.1 (normal: $16.6-48.5$ ) $\mathrm{mg} / \mathrm{dL}$, creatinine 0.6 (normal: 0.5-0.9) mg/dL, AST 250.5 (normal: $\leq 40$ ) IU/L, ALT 408.7 (normal: $\leq 41$ ) IU/L, amylase 73.1 (normal: 28-100) IU/L, lipase 179.3 (normal: 1360) $\mathrm{IU} / \mathrm{L}$, direct bilirrubin 6.31 (normal: $\leq 0.3$ ) $\mathrm{mg} /$ $\mathrm{dL}$, indirect bilirrubin 1.01 (normal: $\leq 0.7$ ) $\mathrm{mg} / \mathrm{dL}$, Gama GT 2,539 (normal 8-61) IU/L, total cholesterol $371 \mathrm{mg} / \mathrm{dL}$, LDL $308 \mathrm{mg} / \mathrm{dL}$, HDL $11 \mathrm{mg} / \mathrm{dL}$, triglycerides $257 \mathrm{mg} / \mathrm{dL}$, glucose $177 \mathrm{mg} / \mathrm{dL}$. Control findings on Day 13 were: hemoglobin $11.7 \mathrm{~g} / \mathrm{dL}$, hematocrit 34.9\%, MCV $89 \mathrm{fL}$, MCH 30\%, leukocytes $8.2 \times 10^{9} / \mathrm{L}$ ( $69 \%$ neutrophils), platelets $418 \times 10^{9} / \mathrm{L}$, ESR 56 (normal: $\leq 15$ ) mm/hour, C-reactive protein 2.3 (normal: $\leq 1$ ) mg/dL, amylase $194 \mathrm{IU} / \mathrm{L}$, lipase $615.6 \mathrm{IU} / \mathrm{L}$, direct bilirrubin $14 \mathrm{mg} / \mathrm{dL}$, indirect bilirrubin 3.8 mg/dL, Gama-GT 2,276 IU/L, AST 205.6 IU/L, ALT 130.3 IU/L, alkaline phosfatase 581.7 (normal 40-130) IU/L, CA 19-9 1,307 (normal: $\leq 40$ ) IU/mL, CA 125 27.7 IU/mL, CEA 9.67 IU/mL. Abdominal tomography with contrast showed dilation of intra and extrahepatic bile ducts, as well as of the Wirsung's duct, in addition to changes indicative of a mild edematous acute pancreatitis (Fig. $1 \mathrm{~A}$ and $1 \mathrm{~B})$. No expansive lesions were found on the head of pancreas. Treatment of pancreatitis included nil per os, intravenous fluid and analgesics for 72 hours, followed by gradual reintroduction of oral diet in accordance with the patient's tolerance. She initially improved with noninvasive management and became afebrile; however, her abdominal pain recurred associated with persistent cholestasis and choluria. On the fourth day of admission an ERCP was performed, showing obstruction of the ampulla of Vater due to infiltrative changes. The findings of biliary brush cytology and of transpapillary biopsy were conclusive for ampullary adenocarcinoma. The patient was then submitted to a Whipple operation with extensive lymph node dissection, and the study of resected specimens confirmed the diagnosis of a well-differentiated ampullary adenocarcinoma with intestinal pattern (Fig. 2). Metastases were detected in six of the examined lymph nodes (four from celiac trunk, and two from hepatic hilum), and a wholebody PET/CT ruled out distant metastases (Fig. 1C). This malignancy was classified as pT3 pN1 
M0. The patient had an uneventful immediate post operative course and, after discharge to home, she was referred to the surveillance of Gastroente- rology and Clinical Oncology outpatient services. She was initially submitted to 28 sessions of adjuvant radiation therapy.
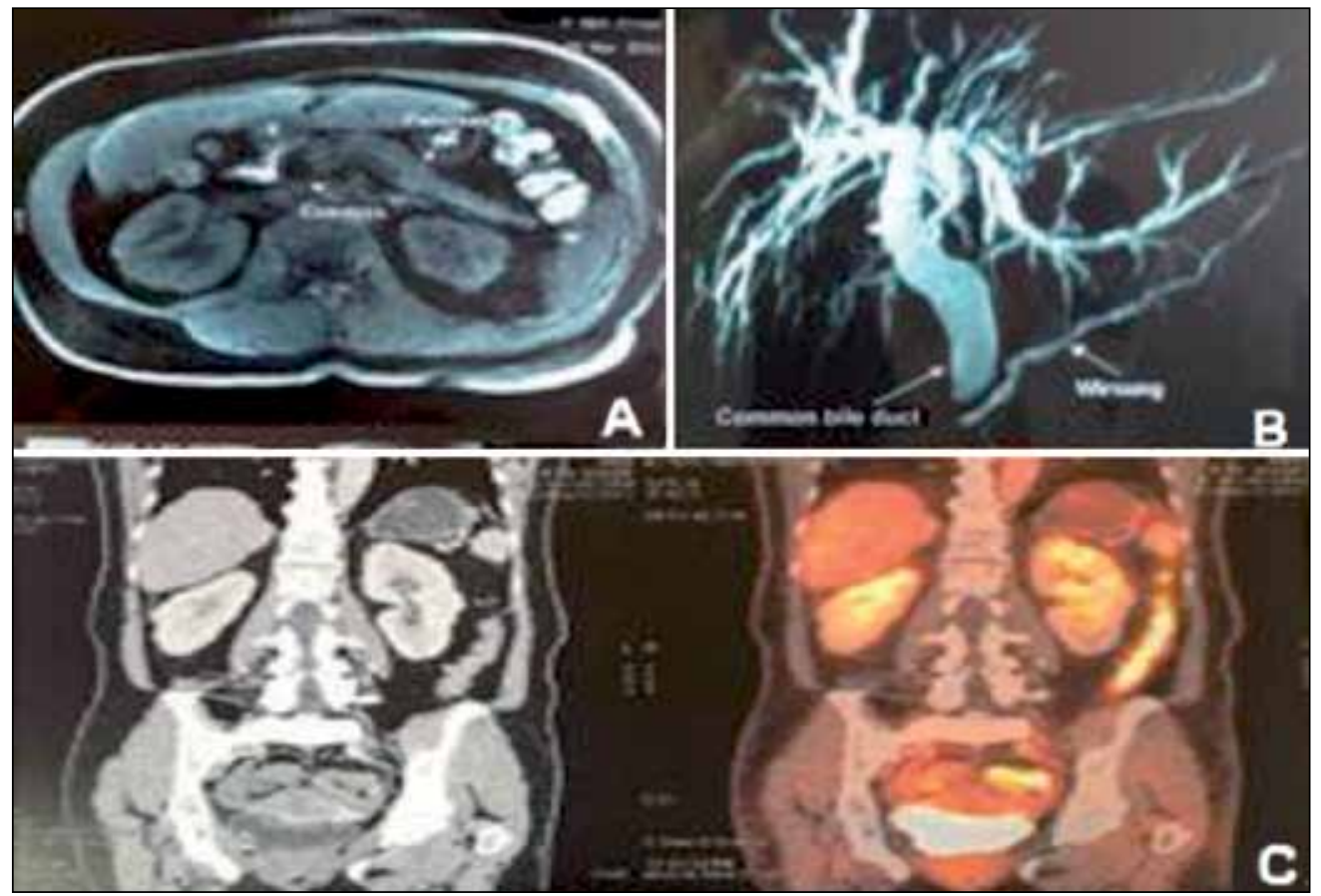

Figure 1. A: Abdominal CT showing dilation of the common bile duct, and discrete focal heterogeneous enhancement of the pancreas, without signs of necrosis or blurring of peripancreatic fat planes; B: Image of contrasted CT revealing dilation of the common bile duct, of the intra-hepatic bile ducts, and of the Wirsung's duct; C: PET/CT images of total body with absence of local or distant hypermetabolic implants.

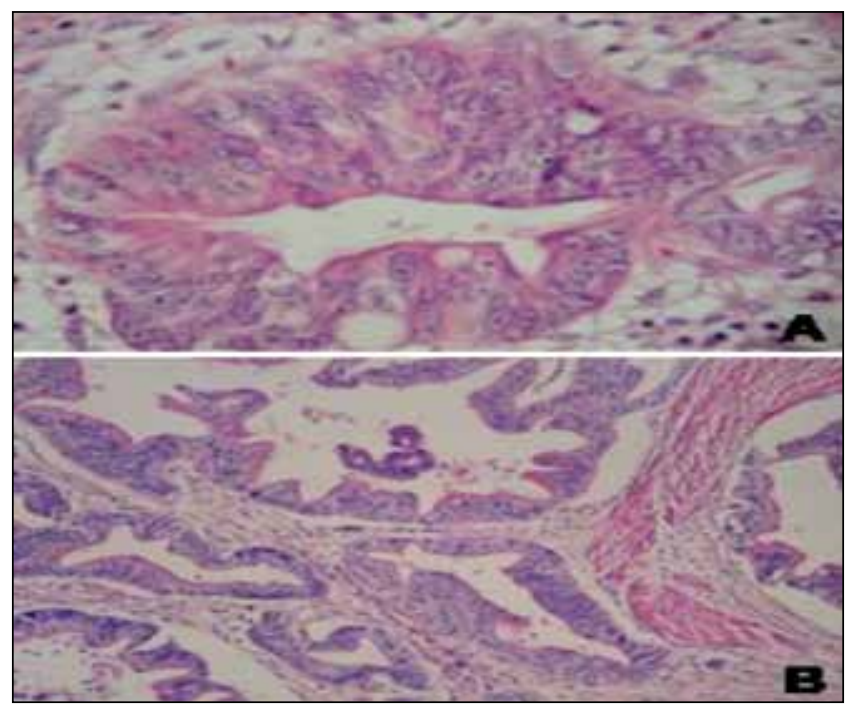

Figure 2. Photomicrography of the welldifferentiated adenocarcinoma from the hepatopancreatic ampulla, with intestinal pattern. A: Neoplastic gland in detail, showing loss of polarity, stratification and nuclear atypia (HE, x 400); B: Aspect of the neoplastic glands surrounded with a desmoplastic stroma (HE, x 100). 


\section{DISCUSSION}

Cholelithiasis is the most common cause of acute pancreatitis in a 56-year-old diabetic, overweighted and multiparous patient. Moreover, she had antecedent of gallstones and cholecystectomy. Therefore, residual or new cholelithiasis and/ or sequels of surgical manipulation on the biliopancreatic area constituted our initial major concerns. On admission, fever, jaundice and abdominal pain raised the hypothesis of cholangitis. However, the low-grade fever was transitory, without shivering, and concomitant with absolutely normal leukocyte formula. Moreover, her body temperature returned to normal soon, with no antibiotic therapy.

Other causal factors of acute pancreatitis include: alcohol, hypertriglyceridemia, hypercalcemia, viral infections, autoimmune diseases, circulatory disturbances, congenital disorders, sphincter of Oddi dysfunction, ampullary and periampullary conditions (tumors, peptic ulcer, polyp, diverticulum), cystic fibrosis, drugs, ERCP, renal failure, blunt trauma, and parasites ${ }^{2,4-6}$.

Additional concern could be about medication-induced acute pancreatitis, because this condition has been scarcely related to metformin, in special in patients with renal failure; moreover, drug-induced acute pancreatitis may appear even after a decade of therapy ${ }^{5,6}$. Nevertheless, the renal function of our patient was normal, and her acute pancreatitis was associated with an ampullary adenocarcinoma. She underwent a pancreaticoduodenectomy, which is the first choice of treatment ${ }^{2,3,7,8}$. After surgical procedure, the drug used to control her diabetes was changed from metformin to insulin, medicine that has been related to decrease in the risk of acute pancreatitis ${ }^{5}$.

Our patient had a T3 N1 M0 tumor at diagnosis, and underwent a radical lymphadenectomy. Histopathology studies of the resected specimens showed negative surgical margins and absence of blood vessels invasion; however, perineural and lymph vascular invasion were observed. Postoperatively, she underwent adjuvant radiotherapy (60 Gy) for locally advanced disease. ${ }^{1}$ Albagi et al retrospectively compared the survival rates of 29 patients submitted to standard lymphadenectomy with 21 patients who underwent radical lymphadenectomy associated with classic gastropancreaticoduodenectomies to treat ampullary adenocarcinomas ${ }^{7}$. Postoperative mortality and morbidity are lower if the tumor is treated at an earlier stage ${ }^{8}$, but more extensive lymphadenectomy showed no statistically significant effect on the survival of the patients ${ }^{7}$. Hatzaras et al reviewed predictors of survival after pancreaticoduodenectomy for periampullary cancers, including preoperative jaundice, microscopic positive margin, lymph node metastasis, lymph vascular, blood vessel, or neural invasion, and grade of differentiation of the tumors ${ }^{8}$. From the 346 periampullary malignancies, 79 (22.8\%) were ampullary carcinomas. Those authors concluded that neural invasion and nodal metastasis, in addition to the tumor biological behavior, represent the main predictive factors of poor outcomes in this setting. Moreover, infections (68/145: 19\%) and fistulas (26/145: $7.6 \%$ ) constituted the two major complications ${ }^{8}$.

In conclusion, recrudescence of signs and symptoms of acute pancreatitis, with elevated serum levels of bilirrubins as well as of hepatic canalicular enzymes, contributed to enhance the suspicion index about the hypothesis of ampullary/ periampullary malignancies. Interestingly, the levels of CA 19-9 were found very high, phenomenon described both in ampullary and periampullary tumors, in addition to pancreatic adenocarcinoma ${ }^{2,9,10}$. Brush cytology and transpapillary biopsy were performed, and characterized the diagnosis of well-differentiated ampullary adenocarcinoma; tumors from pancreas, duodenum, or bile ducts were ruled out ${ }^{2,3,8}$. Case studies can enhance the awareness of primary care physicians about the hypothesis of acute pancreatitis due to ampullary malignancies, a scarcely reported condition. The increased suspicion index about this ominous condition can result in early diagnoses, and better outcomes. 


\section{REFERENCES}

1. Beltrán MB, Roth AD, Mentha G, Allal AS. Adjuvant radio-chemotherapy for extrahepatic biliary tract cancers. BMC Cancer 2011; 11: 267.

2. Petrou A, Bramis K, Williams T, Papalambros A, Mantonakis E, Felekouras E. Acute recurrent pancreatitis: a possible clinical manifestation of ampullary cancer. JOP 2011; 12: 593597.

3. Romiti A, Barucca V, Zullo A, Sarcina I, Di Rocco $\mathrm{R}$, D'Antonio $\mathrm{C}$ et al. Tumors of ampulla of Vater. A case series and review of chemotherapy options. World J Gastrointest Oncol 2012; 4: 60-67.

4. Banks PA, Conwell DL, Toskes PP. The management of acute and chronic pancreatitis. Gastroenterol Hepatol (NY) 2010; 6 (2 Suppl 3): 1-16.

5. Gonzalez-Perez A, Schlienger RG, Rodríguez LAG. Acute pancreatitis in association with type 2 diabetes and antidiabetic drugs. Diabetes Care 2010; 33: 2580-2585.
6. Barreto SG, Tiong L, Williams R. Drug-induced acute pancreatitis in a cohort of 328 patients. A single-centre experience from Australia. JOP 2011; 12: 581-585.

7. Albagli RO, Carvalho GSS, Mali Junior J, Eulálio JMR, MeLo ELR. Comparative study of the radical and standard lymphadenectomy in the surgical treatment of adenocarcinoma of the ampula of Vater. Rev Col Bras Cir 2010; 37: 420-425.

8. Hatzaras I, George N, Muscarella P, Melvin WS, Eluison EC, Bloomston M. Predictors of survival in periampullary cancers following pancreaticoduodenectomy. Ann Surg Oncol 2010; 17: 991-997.

9. Molina V, Visa L, Conill C, Navarro S, Escudero JM, Auge JM, et al. CA 19-9 in pancreatic cancer: retrospective evaluation of patients with suspicion of pancreatic cancer. Tumour Biol. 2011;Dec 29. [Epub ahead of print]

10. Morris-Stiff, Teli M, Jardine N, Puntis MCA. CA 19-9 antigen levels can distinguish between benign and malignant pancreaticobiliary disease. Hepatobiliary Pancreat Dis Int 2009; 8: 620-626. 